\title{
Comparing Continuous Lumbar Plexus Block, Continuous Epidural Block And Continuous Lumbar Plexus Block With A Parasacral Sciatic Nerve Block On Post-Operative Analgesia After Hip Arthroplasty
}

\author{
Dauri M*, Celidonio L, Fabbi E, Nahmias S, Faria S, Coniglione F and Silvi MB
}

Department of Anaesthesiology, Emergency and Intensive Care Medicine, University Hospital of "Tor Vergata”, Rome, Italy

\section{Abstract}

Study Objective: To compare post-operative analgesia obtained by continuous lumbar epidural block (CLEB) versus continuous lumbar plexus block (CLPB) versus CLPB associated with a single shot parasacral sciatic nerve block (CLEBS) after total hip arthroplasty (THA).

Study design: Randomized clinical trial.

Setting: Operating room, postoperative care unit, orthopedic surgical ward

Methods: 78 ASA I-III patients undergoing elective THA were randomly assigned to receive CLEB ( $\mathrm{n}=24,15$ $20 \mathrm{ml}$ of $5 \mathrm{mg} / \mathrm{ml}$ ropivacaine, sufentanil $10 \mu \mathrm{g}$, clonidine $1 \mu \mathrm{g} / \mathrm{ml})$, CLPB $(\mathrm{n}=22,3 \mathrm{mg} / \mathrm{kg}$ of $5 \mathrm{mg} / \mathrm{ml}$ of ropivacaine, max. $40 \mathrm{ml}$, clonidine $1 \mu \mathrm{g} / \mathrm{ml}$, sufentanil $10 \mu \mathrm{g})$ or CLPBS $(\mathrm{n}=23$, CLPB as described above; sciatic nerve: $20 \mathrm{~m}$ of ropivacaine $5 \mathrm{mg} / \mathrm{ml}$, clonidine $1 \mu \mathrm{g} / \mathrm{ml}$ ). All patients received continuous infusion of $2 \mathrm{mg} / \mathrm{ml}$ of ropivacaine, $8 \mathrm{ml} / \mathrm{h}$ for 48 hours. Primary outcome was pain intensity assessment (VAS and VS). Secondary outcomes were postoperative total opioid consumption, hemodynamic stability, motor blockade, blood loss, intraoperative sufentanil and propofol consumption, patient satisfaction and complications.

Results: VAS was lower in the CLEB group than in the CLPB and CLPBS groups respectively for 6 and 12 hours postoperatively (post-surgery $p<0.001,2 \mathrm{~h} p<0.001,6 \mathrm{~h} p<0.001,12 \mathrm{~h} p<0.03$ )(Table 2). Moreover, CLPSB patients reported lower VAS than CLPB patients from the end of the surgery till the $12^{\text {th }}$ follow up hour (Table 2 ). VS was lower in the CLEB group from the end of surgery to 6 h postoperatively (Table 3 ). The CLPB group showed higher morphine consumption than the CLPSB and CLEB groups over $12 \mathrm{~h}$ postoperatively $(p=0.05)$; thereafter, no statistically significant differences were observed between groups at the end of follow up $(48 h)(p=0.4)($ Table 4$)$.

Conclusion: In conclusion, continuous lumbar plexus block in association with single shot sciatic nerve block is a valid alternative to epidural technique in managing postoperative analgesia after THA, with an improved riskbenefit balance.

\section{Introduction}

Regional anesthesia is a validate analgesic treatment option for hip surgery, reducing peri-operative pain and opioid requirements $[1,2]$. Compared with epidural analgesia, the continuous psoas compartment block provides excellent intraoperative and postoperative analgesia with a low incidence of complications for partial hip replacement surgery [3]

Conversely, Biboulet at al affirm that the single injection psoas compartment block is an effective analgesic technique only till the $4^{\text {th }}$ postoperative hour and should not be used routinely after total hip arthroplasty (THA) [4]. Considering the new landmarks proposed by Capdevila [5], a continuous psoas compartment block promotes optimal analgesia after hip arthroplasty, with few side effects. This was also confirmed by other authors [3,6-9]. Moreover, continuous lumbar plexus block is recommended (grade A) for post operative analgesia after THA by the PROSPECT group [6].

In his meta-analysis, Touray ST et al. reported that continuous lumbar plexus block is a safe and effective alternative for analgesia after hip and knee surgery; they also affirmed that more research is required both to define its role in the intraoperative setting and confirm potentially beneficial effects on variables such as peri-operative hemodynamics and blood loss [10].

The aim of this study was to compare postoperative analgesia provided by the continuous lumbar plexus block (CLPB), CLPB associated with parasacral sciatic nerve block (CLPBS) and continuous lumbar epidural block (CLEB) in patients undergoing total hip arthroplasty (THA).

We also compared hemodynamic stability, motor blockade, blood loss, intra-operative sufentanil and propofol consumption, surgeon and patient satisfaction and techniqu-related complications.

\section{Methods}

We conducted a randomized, prospective, double-blind trial in 78 patients who underwent total hip arthroplasty (THA). After the approval of the study design by the "Tor Vergata University Ethics Committee", we enrolled American Society of Anesthesiologists (ASA) physical status class I-II-III patients who were scheduled for

*Corresponding author: Mario Dauri, Department of Anaesthesiology, Emergency and Intensive Care Medicine, University Hospital of "Tor Vergata", Rome, Italy, E-mail: Mario.dauri@uniroma2.it

Received October 11, 2011; Accepted December 05, 2011; Published December 09, 2011

Citation: Dauri M, Celidonio L, Fabbi E, Nahmias S, Faria S, et al. (2011) Comparing Continuous Lumbar Plexus Block, Continuous Epidural Block And Continuous Lumbar Plexus Block With A Parasacral Sciatic Nerve Block On Post-Operative Analgesia After Hip Arthroplasty. J Anesthe Clinic Res 2:177. doi:10.4172/21556148.1000177

Copyright: (c) 2011 Karvandian K, et al. This is an open-access article distributed under the terms of the Creative Commons Attribution License, which permits unrestricted use, distribution, and reproduction in any medium, provided the original author and source are credited. 
unilateral elective THA. The exclusion criteria were: allergy to any local anesthetic; dementia preventing proper comprehension; refusal of the procedure; ASA physical status class IV; use of psychotropic drugs and abuse of alcohol and drugs, severe hematological and coagulation disorders, severe rhythm disorders, neurological disorders (peripheral neuromuscular), local or systemic infection, history of chronic pain, coxo-femoral fractures or dysplasia (because the surgeon needs to test possible sciatic nerve injury due to leg traction for the correction of the dissymmetry and limping), revision of a previous THA. Seventy eight consecutively enrolled patients randomized by a computer-generated list were allocated to one of the three groups. Patients in the CLEB group received continuous lumbar epidural anesthesia, patients in the CLPB group received continuous lumbar plexus block, and patients in the CLPSB group received continuous lumbar plexus block and parasacral sciatic nerve block.

Once the patient was in the operating room, electrocardiogram, heart rate, and peripheral oxygen saturation $\left(\mathrm{SpO}_{2}\right)$ were monitored continuously, and arterial blood pressure (BP) was measured at 5-min intervals using an automatic cycling device (Datex Ohmeda).

In each case, $8 \mathrm{ml} / \mathrm{kg}$ of intravenous (i.v.) isotonic saline was administered as preload. All patients were sedated maintaining spontaneous breathing in order to keep them blind about the chosen technique. Sedation was achieved with Propofol TCI $(1-2 \mu \mathrm{g} / \mathrm{ml})$ (Orchestra ${ }^{\circledR}$ Base Primea, Fresesnius Kabi), after the patient was laterally positioned with the affected limb uppermost.

In the CLEB Group, the patient was placed in the lateral decubitus position with the affected side uppermost. After aseptic skin disinfection and sterile draping, local anesthesia of the skin was applied with 3-4 $\mathrm{ml}$ of lidocaine $20 \mathrm{mg} \mathrm{ml}^{-1}$. An 18G Tuohy needle (Perifix, B Braun, Melsungen, Germany) was advanced from the midline at the L2-L3 or L3-L4 interspace with the needle bevel turned cranially. When the epidural space was identified, using the loss of resistance technique, a $20 \mathrm{G}$ epidural multiorifice catheter was introduced $4-5 \mathrm{~cm}$ inside the epidural space. The catheter was fixed to the skin and a testing dose of $3 \mathrm{ml}$ lidocaine $20 \mathrm{mg} \mathrm{ml}^{-1}$ with epinephrine 1:200.000 was slowly injected. Thereafter, $1 \mathrm{mg} \mathrm{kg}^{-1}$ of ropivacaine (max $100 \mathrm{mg}$ ) was injected through the catheter. In addition, the sensory level of epidural block was assessed by loss of pinprick sensation.

In the CLPB Group, the patient was positioned laterally with the leg to be blocked uppermost. A 120-mm, 21-gauge insulated needle (Polymedic; Temena SARL, Bondy, France) was connected to a peripheral nerve stimulator (Stimuplex; B. Braun, Melsungen, Germany) with an initial current intensity of $1.5 \mathrm{~mA}(2 \mathrm{~Hz}, 0.1$ millisecond). CLPB was performed as described by Capdevila et al [5]. Needle position was judged adequate when quadriceps contractions were still elicited by impulses of 0.3 to $0.5 \mathrm{~mA}$. Then, after accurate negative aspiration a half dose of an overall of $3 \mathrm{mg} \mathrm{kg}^{-1}$ of ropivacaine 5 $\mathrm{mg} \mathrm{ml}^{-1}$ (max $200 \mathrm{mg}$ of ropivacaine), clonidine $1 \mu \mathrm{g} \mathrm{ml}^{-1}$ was injected. Thereafter, a multi-perforated catheter was introduced through the needle and advanced 5-8 cm distally to the needle tip, then, after negative aspiration, the remaining half of the anesthetic mixture was injected through the catheter.

In the CLPSB Group, after CLPB execution the patient remained in the same position and the parasacral sciatic nerve block was performed by using Mansours' landmarks[11]. After identifying the posterior superior iliac spine and the lowest point of the ischiatic tuberosity, a line was drawn between these two points and a mark was made on this line, at $6 \mathrm{~cm}$ inferior to the posterior superior iliac spine. After aseptic skin disinfection of the above mentioned region of the affected limb, a skin wheal was raised with 1 to $2 \mathrm{ml}$ of $20 \mathrm{mg} \mathrm{ml}^{-1}$ lidocaine. A 120-mm, 21-gauge stimulation needle (Polymedic; Temena SARL, Bondy, France) connected to a peripheral nerve stimulator (Stimuplex; B. Braun, Melsungen, Germany) with initial current intensity of 1 $\mathrm{mA}(2 \mathrm{~Hz}, 0.1$ millisecond) was inserted perpendicular to the skin and advanced until motor responses of the posterior tibial (plantar flexion or inversion) or peroneal component (extension of the foot) was elicited. The current output was then progressively diminished until contractions were obtained at an intensity of 0.3 to $0.4 \mathrm{~mA}$, and 20 millilitres of ropivacaine $5 \mathrm{mg} \mathrm{ml}^{-1}$ and clonidine $15 \mu \mathrm{g}$ were then injected through the needle. Both cold and pin-prick tests were used at 30 minutes after anesthesia; moreover, motor block of the affected limb was assessed according to a modified Bromage score method $[0=$ no motor block (nil = 0\%); $1=$ inability to flex the hip (partial $=33 \%) ; 2=$ inability to flex the knee and hip (almost complete $=66 \%$ ); $3=$ inability to flex the ankle, knee and hip (complete $=100 \%$ ) [12]]

The same anesthesiologist, who had experience in both techniques, performed all procedures in all groups. The observer was unaware of patient group allocation; during anesthesia the observer left the room and returned only at the end of the procedure for data collection. Catheters and filters were fixed in the same way to the skin, laterally to the axillary region on the side of the affected limb and then covered carefully (from the middle back to the filter) with white medications in order to avoid any identification by the observer. Only the study coordinator and the anesthesiologist performing the chosen technique were informed, according to the randomization list.

During surgery, patients could receive sedation with propofol in TCI mode (Orchestra ${ }^{\oplus}$ Base Primea, Fresesnius Kabi), Schneider pharmacokinetic protocol (initial target site-effect concentration of 1.5 $\mu \mathrm{g} \mathrm{ml}^{-1}$ ) and opioids (sufentanil 0.2-0.4 $\mu \mathrm{g} / \mathrm{kg}$ ) according to the surgeon's or patient's request; spontaneous breathing was manteined for each patient. No local ansthetics were administered through the perineural catheter during the intra-operative period. At the end of surgery an elastomeric pump with $2 \mathrm{mg} \mathrm{ml}^{-1}$ of ropivacaine at $8 \mathrm{ml} \mathrm{h}^{-1}$ infusion rate was connected to a perineural or epidural catheter; each patient was also connected to a patient-controlled analgesia device (I Pump, Baxter) set to deliver $2 \mathrm{mg}$ morphine bolus, with $10 \mathrm{~min}$ lockout and one hour limit of $8 \mathrm{mg}$ morphine. In the surgical ward, patients could ask for a supplemental analgesic drug (ketorolac $30 \mathrm{mg}$, maximum 90 $\mathrm{mg} /$ day)

In all patients, once-a-day administration of subcutaneous 40 mg enoxaparin (Celexane) was initiated on postoperative day 1 . Both catheters were removed $24 \mathrm{~h}$ after the dose of enoxaparin on postoperative day 2 , and the next dose was administered $2 \mathrm{~h}$ after catheter removal.

Data collection included: demographic (age, sex, weight, height) data; the overall amount of sufentanil or propofol administered intraoperatively; surgery duration. Hemodynamic parameters (heart rate and systolic and diastolic arterial pressure) were collected before and after anesthesia, every 15 minutes during surgery, and at 2, 6, 12, 24, 36 and $48 \mathrm{hrs}$ after surgery.

Both cold and pin-prick tests were used and recorded $30 \mathrm{~min}$ after the block. A modified Bromage score [12] (at rest and on movement) was recorded in order to assess motor block $30 \mathrm{~min}$ after anaesthesia, at the end of surgery, and at $2 \mathrm{~h}, 6 \mathrm{~h}, 12 \mathrm{~h}, 24 \mathrm{~h}, 36 \mathrm{~h}$ and $48 \mathrm{~h}$ in the orthopedic surgery ward. Morphine consumption was recorded at all times during follow up. Pain was assessed using the 10-grade visual analog score 
Citation: Dauri M, Celidonio L, Fabbi E, Nahmias S, Faria S, et al. (2011) Comparing Continuous Lumbar Plexus Block, Continuous Epidural Block And Continuous Lumbar Plexus Block With A Parasacral Sciatic Nerve Block On Post-Operative Analgesia After Hip Arthroplasty. J Anesthe Clinic Res 2:177. doi:10.4172/2155-6148.1000177

Page 3 of 7

system (VAS, ranging from $0=$ no pain to $10=$ absolutely intolerable pain) and a 5-point Verbal Pain Scores (VS; 0 = no pain, $1=$ mild pain, 2 $=$ moderate pain, 3 = severe pain, 4 = very severe pain) before and after anesthesia, at the end of surgery, and again at $2 \mathrm{~h}, 6 \mathrm{~h}, 12 \mathrm{~h}, 24 \mathrm{~h}, 36 \mathrm{~h}$ and $48 \mathrm{~h}$ postoperatively. We also recorded each individual's overall level of satisfaction with the anesthesia and postoperative analgesia, surgeon satisfaction, supplemental analgesic requirements, catheter-related problems, and any complications in the first $48 \mathrm{~h}$ post-operatively.

Surgeon's satisfaction with the anesthetic technique was evaluated at the end of surgery using a 4-point Likert scale that went from "not satisfied" to "very satisfied." Similarly, patients were asked to rate their satisfaction with the pain control using the same scale at the end of follow-up (48 hours) [13].

Primary outcomes of this clinical trial included pain intensity assessment (VAS and VS). Secondary outcomes included total opioid consumption, hemodynamic stability, motor blockade, blood loss, intraoperative sufentanil and propofol consumption, patient satisfaction, and technique- related complications.

\section{Statistical analysis}

To calculate the sample size and $\alpha$ error $=0.05$ (type I error probability for a 2 -sided independent $t$ test) and $\beta$ error $=0.2$ (power $80 \%)$ was accepted. Our hypothesis $\left(\mathrm{H}_{1}\right)$ was to find at least a VAS difference between groups of $20 \mathrm{~mm}$ with a standard deviation $(\sigma)$ of $25 \mathrm{~mm}$, during the post-surgery follow-up. Thus, a sample size of 78 patients (26 patients for each group) was calculated to be appropriate.

Data in the text and tables are reported as mean (SD) and range. On several occasions, the variances between groups were not homogenous (we used the Bartlett test for inequality of population variances), or data were not normally distributed: we thus used the Kruskal Wallis test to check differences between numeric variables. Categorical differences were tested using the Fischer exact method. All $\mathrm{P}$ values were 2-tailed, and $\mathrm{P}<0.05$ was considered statistically significant. The significance between the individual groups was calculated by Post hoc test using the Holm method $(\mathrm{P} \leq 0.05)$. Input data and statistical analysis were performed by using Epi Info Version 3.3.2 software (Centers for Disease Control, Atlanta, USA).

\section{Results}

An overall of 78 patients were enrolled, but only data regarding 69 were analyzed $(\mathrm{CLEB}=24$ patients, $\mathrm{CLPB}=22$ patients, $\mathrm{CLPSB}=23$ patients) (Figure 1).

There were no significant differences between the CLEB, the CLPB and the CLPSB groups in terms of age, sex, BMI, hemodynamic data during the surgery and surgery duration (Table 1).

VAS was lower in the CLEB group than in the CLPB and CLPBS groups respectively for 6 and 12 hours postoperatively (post-surgery $\mathrm{p}<0.001,2 \mathrm{~h} p<0.001,6 \mathrm{~h} \mathrm{p}<0.001,12 \mathrm{~h} \mathrm{p}<0.03$ ) (Table 2). Moreover, CLPSB patients reported lower VAS than CLPB patients from the end of the surgery till $12 \mathrm{~h}$ of follow up (Table 2). VS was lower in the CLEB group from the end of surgery to $6 \mathrm{~h}$ postoperatively (end of surgery $\mathrm{p}=0.02,2 \mathrm{~h} p<0.0001,6 \mathrm{~h} \mathrm{p}=0.001$ ) (Table 3 ). The CLPB group showed higher morphine consumption than the CLPSB and CLEB groups during $12 \mathrm{~h}$ postoperatively $(\mathrm{p}=0.05)$; thereafter, no statistically significant differences were observed between groups at the end of follow up (48h) $(\mathrm{p}=0.4)$ (Table 4). The overall boluses of ketorolac administered did not differ between groups at each end point of the follow up (data not shown).

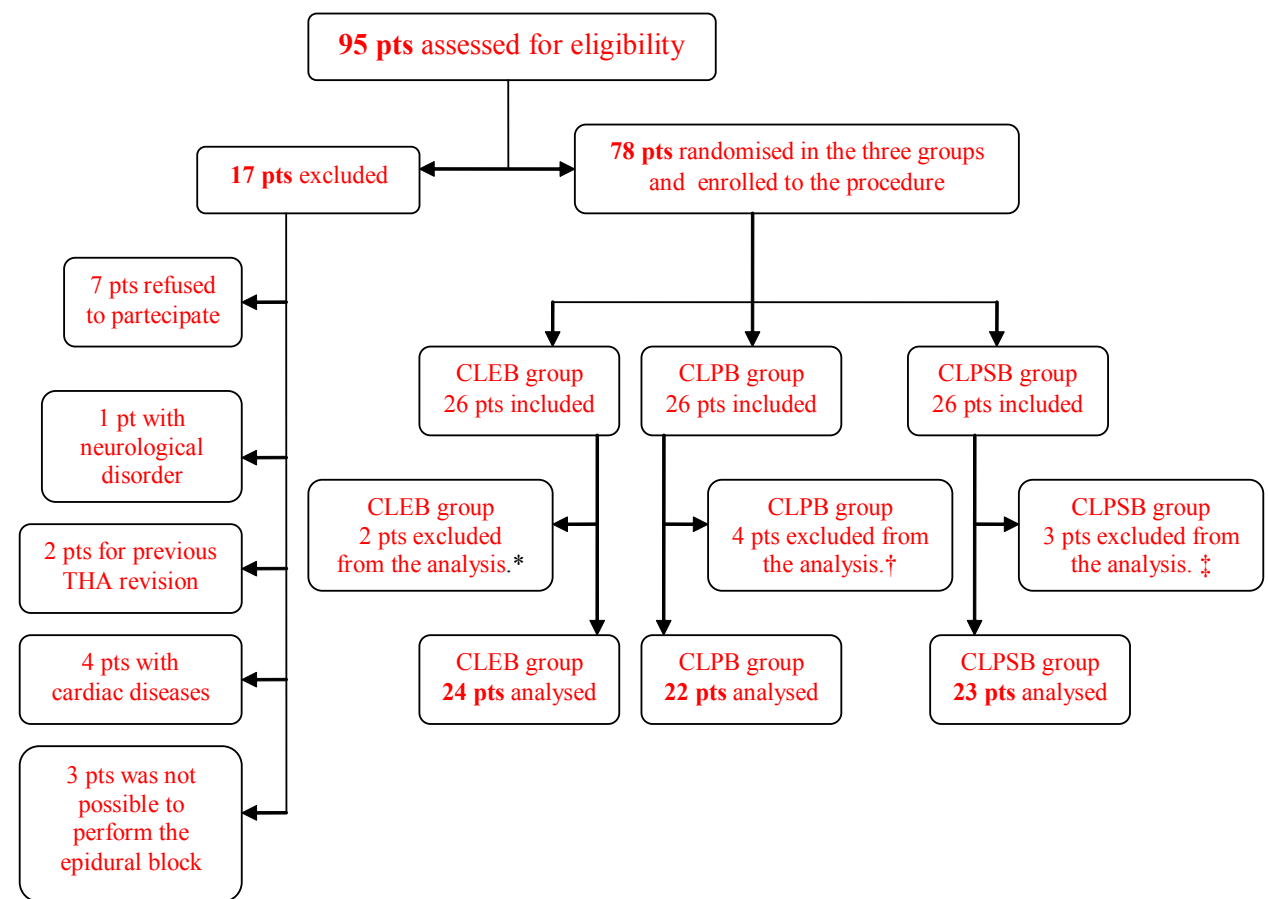

* one patient excluded because of epidural catheter dislocation. The other patient excluded because of incomplete data collection form.

† Three patients excluded because of post-operative perineural catheter. dislocation. One patient excluded because of PCA dysfunction.

₹ Two patients excluded because of post-operative perineural catheter. dislocation. One patient excluded because of incomplete data collection form.

Figure 1: Flow chart of patient enrolment. 
Citation: Dauri M, Celidonio L, Fabbi E, Nahmias S, Faria S, et al. (2011) Comparing Continuous Lumbar Plexus Block, Continuous Epidural Block And Continuous Lumbar Plexus Block With A Parasacral Sciatic Nerve Block On Post-Operative Analgesia After Hip Arthroplasty. J Anesthe Clinic Res 2:177. doi:10.4172/2155-6148.1000177

Page 4 of 7

\begin{tabular}{|c|c|c|c|c|}
\hline Characteristics & CLEB & CLPB & CLPSB & p-value \\
\hline Age, years & $67.6 \pm 7.8(52-78)$ & $68.4 \pm 8.8(53-85)$ & $66.3 \pm 9.7(50-79)$ & 0.6 \\
\hline Sex, M/F & $14 / 10$ & $9 / 13$ & $10 / 12$ & 0.5 \\
\hline BMI, kg m-2 & $27.5 \pm 4.2(21-35)$ & $28.1 \pm 4.1(22-35)$ & $26.9 \pm 3.7(20-33)$ & 0.7 \\
\hline ASA I / II / III & $3 / 16 / 5$ & $4 / 14 / 4$ & $5 / 11 / 7$ & 0.7 \\
\hline Surgery duration, $\min$ & $95.4 \pm 26.6(60-155)$ & $101.3 \pm 31.5(60-175)$ & $96.1 \pm 34.1(60-180)$ & 0.7 \\
\hline \multicolumn{5}{|l|}{ Haemodynamics } \\
\hline \multicolumn{5}{|l|}{ Pre-anesthesia } \\
\hline Mean arterial pressure, $\mathrm{mmHg}$ & $95.2 \pm 13.3(59-113)$ & $98.4 \pm 12.8(70-119)$ & $100.1 \pm 13.2(70-121)$ & 0.6 \\
\hline Heart rate & $72.7 \pm 8.0(52-85)$ & $73.4 \pm 8.8(55-93)$ & $71.1 \pm 5.1(63-80)$ & 0.5 \\
\hline \multicolumn{5}{|l|}{ Post-anesthesia } \\
\hline Mean arterial pressure, $\mathrm{mmHg}$ & $72.7 \pm 12.6(52-101)$ & $88.0 \pm 14.8(63-114)$ & $89.6 \pm 18.6(59-116)$ & 0.002 \\
\hline Heart rate & $68.8 \pm 11.3(46-87)$ & $72.1 \pm 10.8(48-90)$ & $69.2 \pm 15.4(48-120)$ & 0.5 \\
\hline \multicolumn{5}{|l|}{ intra-surgery } \\
\hline \multicolumn{5}{|l|}{ Incision } \\
\hline Mean arterial pressure, $\mathrm{mmHg}$ & $73.2 \pm 16.2(48-114)$ & $71.0 \pm 14.6(55-111)$ & $72.5 \pm 15.0(49-95)$ & 0.8 \\
\hline Heart rate & $61.8 \pm 9.7(48-85)$ & $62.6 \pm 13.2(42-87)$ & $62.5 \pm 7.7(49-75)$ & 0.9 \\
\hline \multicolumn{5}{|l|}{ Femur cutting } \\
\hline Mean arterial pressure, $\mathrm{mmHg}$ & $70.0 \pm 18.2(44-118)$ & $71.8 \pm 12.3(50-98)$ & $67.2 \pm 9.3(54-86)$ & 0.5 \\
\hline Heart rate & $61.2 \pm 10.5(44-85)$ & $63.7 \pm 12.1(48-84)$ & $60.8 \pm 7.2(51-76)$ & 0.8 \\
\hline \multicolumn{5}{|l|}{ Acetabulus drilling } \\
\hline Mean arterial pressure, $\mathrm{mmHg}$ & $72.4 \pm 19.4(51-117)$ & $70.2 \pm 10.7(52-94)$ & $66.6 \pm 10.1(46-89)$ & 0.7 \\
\hline Heart rate & $62.3 \pm 11.5(43-85)$ & $64.8 \pm 13.5(46-84)$ & $61.5 \pm 8.6(51-77)$ & 0.8 \\
\hline \multicolumn{5}{|l|}{ End of surgery } \\
\hline Mean arterial pressure, $\mathrm{mmHg}$ & $77.3 \pm 16.9(55-113)$ & $83.5 \pm 14.6(62-119)$ & $79.4 \pm 7.7(63-97)$ & 0.3 \\
\hline Heart rate & $68.1 \pm 10.3(50-85)$ & $66.6 \pm 11.4(45-87)$ & $68.9 \pm 13.3(45-97)$ & 0.8 \\
\hline
\end{tabular}

Table 1: Patient demographics and surgical data

Intra-operative overall propofol consumption was significantly lower in the CLEB group $(342 \pm 382 \mathrm{mg}$ ) than in the CLPB group $(732 \pm 367 \mathrm{mg})(\mathrm{p}=0.005)$; however, there were no differences between CLPSB $(540 \pm 393 \mathrm{mg})$ and CLEB patients $(\mathrm{p}=0.09)$ (Table 2). Intraoperative sufentanil consumption was significantly lower in CLEB $(7.5 \pm 8.7 \mu \mathrm{g})$ and CLPSB $(6.1 \pm 5.4 \mu \mathrm{g})$ patients than in the CLPB group $(14.0 \pm 12.9 \mu \mathrm{g})(\mathrm{p}=0.02$ and $\mathrm{p}=0.05$ respectively).

Motor block of the operated side was significantly pronounced in the CLPSB group till $24 \mathrm{hrs}$ after surgery as reported by the Bromage scale (after surgery $\mathrm{p}=0.01,2 \mathrm{~h} p<0.0001,6 \mathrm{~h} \mathrm{p}=0.001,12 \mathrm{~h} \mathrm{p}<0.0001$, $24 \mathrm{~h} \mathrm{p}=0.004)$ (Table 3$)$.

No significant differences were found in hemodynamic data throughout the post-operative follow up period (data not shown).

Post-operative blood loss from the drainages was similar in groups; the hematic hemoglobin concentration was similar between groups before surgery, $24 \mathrm{~h}$ after surgery and $48 \mathrm{~h}$ postoperatively (Table 5). An overall of 23 patients were transfused after surgery and no significant differences were observed between groups regarding the transfused blood amount (Table 5).

Regarding complications (Table 6), there were no differences in postoperative nausea and vomiting (PONV) between groups $(p=0.6)$. Post-operative hypotension was recorded more frequently in the CLEB group than in the CLPB or CLPSB groups but the difference was not statistically relevant $(p=0.2)$. Only one patient of the CLPB group reported post-operative pruritus. There were no general or local adverse effects linked to the epidural or perineural injection of ropivacaine.

At the end of the 48 hour follow up period, there was no statistical difference either in patient or in surgeon satisfaction (respectively $\mathrm{p}=0.5, \mathrm{p}=0.6$ ) (Data not shown).

\section{Post hoc analysis}

To compare the relative efficacies of these three interventions, the individual reductions in postoperative VAS score were analyzed using ANOVA with the Holm post hoc test.

In 69 randomized patient, the mean reduction in post surgery, $2 \mathrm{~h}$, $6 \mathrm{~h}$ and $12 \mathrm{~h}$ VAS score of the CLEB group with those of the CLPB group, was significantly higher (Holm: post surgery $\mathrm{p}=0.000 ; 2 \mathrm{~h} p=0.000 ; 6 \mathrm{~h}$ $\mathrm{p}=0.000 ; 12 \mathrm{~h} \mathrm{p}=0.013)$.

Similarly, on comparing the mean reduction in post surgery, $2 \mathrm{~h}$, $6 \mathrm{~h}$ and $12 \mathrm{~h}$ VAS score of the CLPSB group with the CLPB group, the CLPSB showed a significantly higher reduction (Holm: post surgery $\mathrm{p}=0.002 ; 2 \mathrm{~h} \mathrm{p}=0.000 ; 6 \mathrm{~h} \mathrm{p}=0.000 ; 12 \mathrm{~h} \mathrm{p}=0.006$ ).

However, when the effectiveness of CLEB and CLPSB on the reduction of post-surgery, $2 \mathrm{~h}, 6 \mathrm{~h}$ and $12 \mathrm{~h}$ VAS score were compared, there was no significant difference (Holm $P>0.05$ for all time of follow up) between the two techniques. Hence, it was deduced that CLEB and CLPSB were equally effective.

\begin{tabular}{|l|l|l|l|l|}
\hline \multicolumn{5}{|c|}{ VAS at rest (mm) } \\
\hline \multicolumn{1}{|c|}{ Follow-up } & \multicolumn{1}{|c|}{ CLEB } & \multicolumn{1}{c|}{ CLPB } & \multicolumn{1}{c|}{ CLPSB } & P-value \\
\hline pre-surgery & $2.8 \pm 5.2(0-17)$ & $3.2 \pm 6.8(0-26)$ & $3.4-5.5(0-15)$ & 0.9 \\
\hline post-surgery & $3.4 \pm 9.8(0-42)$ & $27.7 \pm 24.0(0-68)$ & $11.1 \pm 19.7(0-44)$ & $<0.001$ \\
\hline $\mathbf{2}$ hours & $2.0 \pm 8.0(0-37)$ & $30.0 \pm 22.2(0-78)$ & $10.9 \pm 16.6(0-54)$ & $<\mathbf{0 . 0 0 1}$ \\
\hline $\mathbf{6}$ hours & $6.7 \pm 14.2(0-50)$ & $25.5 \pm 16.8(0-51)$ & $7.5 \pm 11.2(0-43)$ & $<\mathbf{0 . 0 0 1}$ \\
\hline $\mathbf{1 2}$ hours & $15.7 \pm 19.1(0-61)$ & $30.5 \pm 21.3(0-78)$ & $14.6 \pm 18.8(0-60)$ & $\mathbf{0 . 0 3}$ \\
\hline $\mathbf{2 4}$ hours & $9.5 \pm 15.0(0-65)$ & $17.2 \pm 18.3(0-50)$ & $19.0 \pm 15.7(0-49)$ & 0.1 \\
\hline $\mathbf{3 6}$ hours & $5.9 \pm 11.0(0-47)$ & $10.2 \pm 15.5(0-48)$ & $13.3 \pm 14.5(0-50)$ & 0.2 \\
\hline $\mathbf{4 8}$ hours & $4.5 \pm 9.8(0-43)$ & $9.1 \pm 12.6(0-43)$ & $11.4 \pm 14.4(0-49)$ & 0.2 \\
\hline
\end{tabular}

Table 2: VAS at rest listed as mean \pm SD or number of patients per category. 
Citation: Dauri M, Celidonio L, Fabbi E, Nahmias S, Faria S, et al. (2011) Comparing Continuous Lumbar Plexus Block, Continuous Epidural Block And Continuous Lumbar Plexus Block With A Parasacral Sciatic Nerve Block On Post-Operative Analgesia After Hip Arthroplasty. J Anesthe Clinic Res 2:177. doi:10.4172/2155-6148.1000177

Page 5 of 7

\begin{tabular}{|c|c|c|c|c|c|c|c|c|c|c|c|c|}
\hline \multicolumn{13}{|c|}{ Verbal Pain Score (VS) } \\
\hline & \multicolumn{3}{|c|}{ no pain } & \multicolumn{3}{|c|}{ mild pain } & \multicolumn{3}{|c|}{ moderate pain } & \multicolumn{3}{|c|}{ severe pain } \\
\hline Follow-up* & CLEB & CLPB & CLPSB & CLEB & CLPB & CLPSB & CLEB & CLPB & CLPSB & CLEB & CLPB & CLPSB \\
\hline pre-surgery & $18(75.0)$ & $16(72.8)$ & $16(69.6)$ & $6(25.0)$ & $4(18.2)$ & $6(26.1)$ & $0(0.0)$ & $1(4.5)$ & $1(4.3)$ & $0(0.0)$ & $1(4.5)$ & $0(0.0)$ \\
\hline $\begin{array}{l}\text { post-sur- } \\
\text { gery }\end{array}$ & $19(79.2)$ & $7(31.8)$ & $13(56.5)$ & $4(16.7)$ & $5(22.7)$ & $6(26.2)$ & $1(4.1)$ & $8(36.4)$ & $3(13.0)$ & $0(0.0)$ & $2(9.1)$ & $1(4.3)$ \\
\hline 2 hours & $20(83.4)$ & $1(4.5)$ & $12(52.2)$ & $2(8.3)$ & $10(45.5)$ & $7(30.4)$ & $2(8.3)$ & $8(36.4)$ & $2(8.7)$ & $0(0.0)$ & $3(13.6)$ & $2(8.7)$ \\
\hline 6 hours & $19(79.2)$ & $4(18.2)$ & $12(52.2)$ & $3(12.5)$ & $9(40.9)$ & $8(34.8)$ & $2(8.3)$ & $8(36.4)$ & $2(8.7)$ & $0(0.0)$ & $1(4.5)$ & $1(4.3)$ \\
\hline 12 hours & $10(41.7)$ & $3(13.6)$ & $11(47.8)$ & $9(37.5)$ & $9(40.9)$ & $6(26.1)$ & $4(16.7)$ & $7(31.8)$ & $4(17.4)$ & $1(4.1)$ & $3(13.6)$ & $2(8.7)$ \\
\hline 24 hours & $11(45.9)$ & $8(36.4)$ & $8(34.9)$ & $9(37.5)$ & $8(36.4)$ & $9(39.1)$ & $3(12.5)$ & $5(22.7)$ & $5(21.7)$ & $1(4.1)$ & $1(4.5)$ & $1(4.3)$ \\
\hline 36 hours & $14(58.4)$ & $10(45.5)$ & $10(43.5)$ & $8(33.3)$ & $7(31.8)$ & $10(43.5)$ & $2(8.3)$ & $3(13.6)$ & $3(13.0)$ & $0(0.0)$ & $2(9.1)$ & $0(0.0)$ \\
\hline 48 hours & $18(75.0)$ & $13(59.1)$ & $14(60.9)$ & $4(16.7)$ & $6(27.3)$ & $6(26.1)$ & $2(8.3)$ & $3(13.6)$ & $3(13.0)$ & $0(0.0)$ & $0(0.0)$ & $0(0.0)$ \\
\hline \multicolumn{13}{|c|}{ Bromage scale $^{\circ}$} \\
\hline & \multicolumn{3}{|c|}{ nil $(0 \%)$} & \multicolumn{3}{|c|}{ partial $(33 \%)$} & \multicolumn{3}{|c|}{ almost complete $(66 \%)$} & \multicolumn{3}{|c|}{ complete $(100 \%)$} \\
\hline Follow-up ${ }^{\circ}$ & CLEB & CLPB & CLPSB & CLEB & CLPB & CLPSB & CLEB & CLPB & CLPSB & CLEB & CLPB & CLPSB \\
\hline Pre-surgery & $14(58.3)$ & $3(13.6)$ & $5(21.7)$ & $7(29.2)$ & $7(31.8)$ & $3(13.1)$ & $1(4.2)$ & $10(45.5)$ & $8(34.8)$ & $2(8.3)$ & $2(9.1)$ & $7(30.4)$ \\
\hline $\begin{array}{l}\text { post-sur- } \\
\text { gery }\end{array}$ & $10(41.7)$ & $3(13.6)$ & $0(0.0)$ & $5(20.8)$ & $5(22.6)$ & $2(8.7)$ & $5(20.8)$ & $6(26.4)$ & $4(17.4)$ & $4(16.7)$ & $8(36.4)$ & $17(73.9)$ \\
\hline 2 hours & $10(41.7)$ & $1(4.5)$ & $0(0.0)$ & $6(25.0)$ & $5(22.8)$ & $2(8.7)$ & 4 (16.6) & $7(31.8)$ & $5(21.7)$ & $4(16.7)$ & 9 (40.9) & 16 (69.6) \\
\hline 6 hours & $9(37.5)$ & $1(4.5)$ & $0(0.0)$ & $8(33.3)$ & $7(31.9)$ & $3(13.1)$ & $4(16.6)$ & $5(22.7)$ & $7(30.4)$ & $3(12.5)$ & $9(40.9)$ & $13(56.5)$ \\
\hline 12 hours & $10(41.7)$ & $3(13.6)$ & $0(0.0)$ & $12(50.0)$ & $10(45.5)$ & $5(21.7)$ & $1(4.2)$ & $4(18.2)$ & $10(43.5)$ & $1(4.1)$ & $5(22.7)$ & $8(34.8)$ \\
\hline 24 hours & $10(41.7)$ & $3(13.6)$ & $2(8.7)$ & $13(54.1)$ & $10(45.5)$ & $10(43.5)$ & $1(4.2)$ & $8(36.4)$ & $7(30.4)$ & $0(0.0)$ & $1(4.5)$ & $4(17.4)$ \\
\hline 36 hours & $11(45.9)$ & $4(18.2)$ & $5(21.7)$ & $11(45.8)$ & $11(50.0)$ & $10(43.5)$ & $2(8.3)$ & $7(31.8)$ & $8(34.8)$ & $0(0.0)$ & $0(0.0)$ & $0(0.0)$ \\
\hline 48 hours & $11(45.9)$ & $6(27.3)$ & $7(30.5)$ & $11(45.8)$ & $12(54.5)$ & $11(47.8)$ & $2(8.3)$ & $4(18.2)$ & $5(21.7)$ & $0(0.0)$ & $0(0.0)$ & $0(0.0)$ \\
\hline
\end{tabular}

${ }^{*}$ statistical differences were observed at the end of the surgery $(p=0.02), 2$ hours $(p<0.001), 6$ hours $(p=0.001)$

${ }^{\circ}$ statistical differences were observed at before surgery $(p=0.001)$, after surgery $(p=0.001)$, at 2 hours $(p<0.0001)$, at 6 hours $(p=0.001)$, at 12 hours $(p<0.0001)$, at 24 hours $(p=0.004)$. At 36 hours and 48 hours no statistically significant differences were observed, $p=0.1$ and $p=0.6$ respectively.

Table 3: Verbal pain score (VS) and Bromage scale.

\begin{tabular}{|l|l|l|l|l|}
\hline & CLEB $(\mathbf{n}=\mathbf{2 4})$ & CLPB(n=22) & CLPBS(n=23) & $1.5 \pm 2.0$ \\
\hline Morphine $12 \mathrm{~h}$ & $1.6 \pm 2.6$ & $3.0 \pm 2.7$ & $7.8 \pm 6.9$ \\
\hline Morphine $48 \mathrm{~h}$ & $7.4 \pm 6.9$ & $9.7 \pm 7.0$ & \\
\hline
\end{tabular}

Table 4: postoperative morphine consumption (boluses number) listed as mean \pm SD or number of patients per category.

\begin{tabular}{|c|c|c|c|}
\hline & CLEB $(n=24)$ & CLPB(n=22) & CLPBS(n=23) \\
\hline Blood loss & $818.6 \pm 245.6 \mathrm{ml}$ & $680.8 \pm 365.6 \mathrm{ml}$ & $751.8 \pm 359.4 \mathrm{ml}(p=0.3)$ \\
\hline \multicolumn{4}{|l|}{ Hemoglobin lev: } \\
\hline - before surgery & $13.2 \pm 1.3 \mathrm{~g} \mathrm{dL}-1$ & $12.9 \pm 1.6 \mathrm{~g} \mathrm{dL}-1$ & $13.0 \pm 1.5 \mathrm{~g} \mathrm{dL}-1 \quad(p=0.9)$ \\
\hline - 24h postoperatively & $10.3 \pm 0.9 \mathrm{~g} \mathrm{dL}-1$ & $10.8 \pm 1.3 \mathrm{~g} \mathrm{dL}-1$ & $10.6 \pm 1.2 \mathrm{~g} \mathrm{dL}-1 \quad(p=0.4)$ \\
\hline - 48h postoperatively & $9.8 \pm 1.0 \mathrm{~g} \mathrm{dL}-1$ & $10.6 \pm 1.4 \mathrm{~g} \mathrm{dL}-1$ & $10.3 \pm 1.2 \mathrm{~g} \mathrm{dL}-1 \quad(p=0.2)$ \\
\hline Blood transfused & $428 \pm 145.5 \mathrm{ml}$ & $317 \pm 132.5 \mathrm{ml}$ & $450 \pm 187 \mathrm{ml}$ \\
\hline
\end{tabular}

Table 5: postoperative blood loss, hemoglobin levels and transfusion requirement listed as mean \pm SD or number of patients per category.

\begin{tabular}{|l|l|l|l|}
\hline & CLEB $(\mathbf{n = 2 4 )}$ & CLPB (n=22) & CLPBS (n=23) \\
\hline PONV & $6(25 \%)$ & $5(22.7 \%)$ & $3(13.0 \%)$ \\
\hline Hypotention & $5(20.8 \%)$ & $1(4.5 \%)$ & $1(4.3 \%)$ \\
\hline pruritus & $1(4.2 \%)$ & $0(0 \%)$ & $0(0 \%)$ \\
\hline
\end{tabular}

Table 6: postoperative complications reported in number of patients and percentage.

\section{Discussion}

In this trial we can confirm that the epidural technique guarantees a high level of intra-operative anesthesia and post-operative analgesia; however, lumbar plexus block in association with parasacral sciatic nerve block totally involves the sensitive surgical area14 guaranteeing a good level of intraoperative anesthesia [15]. Regarding the postoperative period, we found that continuous lumbar plexus block technique, especially in association with sciatic nerve block, achieved a good level of analgesia, in accordance with data shown in the literature; in fact, we observed similar pain scores in the CLPB group to those reported by other authors who used continuous or single shot lumbar plexus technique $[3,4,9]$. However, the post-operative VAS score was always $<30 \mathrm{~mm}$ in all groups and the difference between them was $<2$ points; it could thus be argued that it would be unlikely to be clinically meaningful. For this reason, every aspect of each technique must be evaluated.

As in our trial, the literature shows that lumbar plexus block leads to monolateral motor block, allowing early post-operative mobilization and also guaranteeing a good level of analgesia, with no associated hemodynamic instability 3 . However, motor block of the operated side was deeper in the CLPSB group for $24 \mathrm{~h}$ of follow-up. 
Citation: Dauri M, Celidonio L, Fabbi E, Nahmias S, Faria S, et al. (2011) Comparing Continuous Lumbar Plexus Block, Continuous Epidural Block And Continuous Lumbar Plexus Block With A Parasacral Sciatic Nerve Block On Post-Operative Analgesia After Hip Arthroplasty. J Anesthe Clinic Res 2:177. doi:10.4172/2155-6148.1000177

Page 6 of 7

The epidural block technique could be difficult to perform in cases of spinal calcification; moreover, degenerative spinal disease may exacerbate the difficulty in elderly patients; in our study, it was not possible to perform epidural block in 3 patients because of spinal calcification and degeneration.

In addition, Turker et al. [3] reported that the epidural block required significantly more attempts than the psoas compartment block, which prolonged the anesthetic procedure time in the epidural group [3]; however we did no't record the time needed for the anesthetic techniques.

We are aware that each technique has several complications; some of them could be linked to thromboprophylaxis, recommended for at least 10 days for THA [16]. Anticoagulation therapy could also be necessary for several patients' comorbidities. This could be relevant in patients receiving epidural anesthesia/analgesia in whom an epidural hematoma could lead to paraplegia [17].On the other hand, the literature shows that continuous lumbar plexus block related-complications include renal subcapsular [18] or psoas haematoma $[19,20]$; in our opinion , complication frequency and severity must be taken into consideration in the anesthetic technique choice, avoiding a polyphemic point of view and always considering the risk/benefit balance.

None of the individuals in any of the groups we studied developed these serious problems. The number of cases we studied was too small to compare the safety of epidural vs. psoas blocks; however, our findings support the conclusion of a prospective survey of 103,730 cases, which conclude that peripheral nerve blocks are relatively safe in terms of major complications [21].

Peripheral nerve blocks are thought to cause less nausea-vomiting and urinary retention than neuroaxial blocks [22]. In agreement with this finding, we observed more cases of nausea-vomiting in the CLEB group. The lower rate of these complications in patients with peripheral nerve blocks contributed to greater patient satisfaction and earlier mobilization.

Compared to epidural block, lumbar plexus block alone or associated with sciatic nerve block caused limited unilateral sympathectomy, and therefore only minimal hemodynamic alterations. Thereafter, intraoperative mean arterial pressure was similar between groups, probably due to the use of associated sedative and opioid drugs.

Reduced blood loss with lumbar plexus block has previously been described $[23,24]$. However, the postoperative blood loss in our study was not significantly different between groups, probably because of clinically similar pain scores and arterial blood pressures throughout the post-operative period.

In conclusion, continuous lumbar plexus block in association with single shot sciatic nerve block is a valid alternative to epidural technique in managing postoperative analgesia after THA, with an improved riskbenefit balance.

\section{Acknowledgments}

No conflicts of interest to declare. This is a no profit clinical trial. We thank Dr. Skerdilajd Faria for statistical analysis.

\section{References}

1. Hebl JR, Dilger JA, Byer DE, Kopp SL, Stevens SR, et al. (2008) A pre-emptive multimodal pathway featuring peripheral nerve block improves perioperative outcomes after major orthopedic surgery. Reg Anesth Pain Med 33: 510-517.

2. Indelli PF, Grant SA, Nielsen K, Vail TP (2005) Regional anesthesia in hip surgery. Clin Orthop Relat Res 441: 250-255.
3. Türker G, Uçkunkaya N, Yavaşçaoğlu B, Yilmazlar A, Ozçelik S (2003) Comparison of the catheter-technique psoas compartment block and the epidural block for analgesia in partial hip replacement surgery. Acta Anaesthesiol Scand 47: 30-36.

4. Biboulet P, Morau D, Aubas P, Bringuier-Branchereau S, Capdevila X (2004) Postoperative analgesia after total-hip arthroplasty: Comparison of intravenous patient-controlled analgesia with morphine and single injection of femoral nerve or psoas compartment block. a prospective, randomized, double-blind study. Reg Anesth Pain Med 29: 102-109.

5. Capdevila X, Macaire P, Dadure C, Choquet O, Biboulet P, et al. (2002) Continuous psoas compartment block for postoperative analgesia after total hip arthroplasty: new landmarks, technical guidelines, and clinical evaluation. Anesth Analg 94: 1606-1613

6. Fischer HB, Simanski CJ (2005) A procedure- specific systematic review and consensus recommendations for analgesia after total hip replacement Anaesthesia 60: 1189-1202.

7. Stevens RD, Van Gessel E, Flory N, Fournier R, Gamulin Z (2000) Lumba plexus block reduces pain and blood loss associated with total hip arthroplasty. Anesthesiology 93: 115-121.

8. Pagnano MW, Hebl J, Horlocker T (2006) Assuring a painless total hip arthroplasty: a multimodal approach emphasizing peripheral nerve blocks. J Arthroplasty 21: 80-84

9. Siddiqui ZI, Cepeda MS, Denman W, Schumann R, Carr DB (2007) Continuous lumbar plexus block provides improved analgesia with fewer side effects compared with systemic opioids after hip arthroplasty: a randomized controlled trial. Reg Anesth Pain Med 32: 393-398.

10. Touray ST, de Leeuw MA, Zuurmond WW, Perez RS (2008) Psoas compartmen block for lower extremity surgery: a meta-analysis. Br J Anaesth 101: 750-760.

11. Mansour NY (1993) Reevaluating the sciatic nerve block: another landmark for consideration. Reg Anesth 18: 322-323.

12. Kampe S, Kiencke P, Delis A, Auweiler M, König DP et al. (2003) The continuous epidural infusion of ropivacaine $0.1 \%$ with 0.5 microg $\mathrm{mL}-1$ sufentanil provides effective postoperative analgesia after total hip replacement: a pilot study. Can J Anaesth 50: 580-585.

13. Brown DL, Warner ME, Schroeder DR, Offord KP (1997) Effect of intraoperative anesthetic events on postoperative patient satisfaction. Mayo Clin Proc 72: 2025.

14. Wertheimer LG (1952) The sensory nerves of the hip joint. J Bone Joint Surg Am 34: 477-487.

15. Buckenmaier 3rd CC, Xenos JS, Nilsen SM (2002) Lumbar plexus block with perineural catheter and sciatic nerve block for total hip arthroplasty. $J$ Arthroplasty 17: 499-502

16. Geerts WH, Pineo GF, Heit JA, Bergqvist D, Lassen MR et al. (2004) Prevention of venous thromboembolism: the Seventh ACCP Conference on Antithrombotic and Thrombolytic Therapy. Chest 126: 338S-400S

17. Sidiropoulou T, Pompeo E, Bozzao A, Lunardi P, Dauri M (2003) Epidura hematoma after thoracic epidural catheter removal in the absence of risk factors. Reg Anesth Pain Med 28: 531-534.

18. Aida S, Takahashi H, Shimoji K (1996) Renal subcapsular hematoma afte lumbar plexus block. Anesthesiology 84: 452-455.

19. Weller RS, Gerancher JC, Crews JC, Wade KL (2003) Extensive retroperitoneal hematoma without neurologic deficit in two patients who underwent lumbar plexus block and were later anticoagulated. Anesthesiology 98: 581-585.

20. Dauri M, Faria S, Celidonio L, Tarantino U, Fabbi E et al. Retroperitonea haematoma in a patient with continuous psoas compartment block and enoxaparin administration for total knee replacement. Br J Anaesth 103: 309 310

21. Auroy Y, Narchi P, Messiah A, Litt L, Rouvien B et al. (1997) Serious complications related to regional anesthesia results of a prospective survey in France. Anesthesiology 87: 479-486.

22. Horlocker TT (1998) Peripheral nerve blocks: regional anesthesia for the new millennium. Reg Anesth Pain Med 23: 237-240. 
Citation: Dauri M, Celidonio L, Fabbi E, Nahmias S, Faria S, et al. (2011) Comparing Continuous Lumbar Plexus Block, Continuous Epidural Block And Continuous Lumbar Plexus Block With A Parasacral Sciatic Nerve Block On Post-Operative Analgesia After Hip Arthroplasty. J Anesthe Clinic Res 2:177. doi:10.4172/2155-6148.1000177

Page 7 of 7

23. Stevens RD, Van Gessel E, Flory N, Fournier R, Gamulin Z (2000) Lumbar plexus block reduces pain and blood loss associated with total hip arthroplasty. Anesthesiology 93: 115-121.
24. Modig J, Karlstrom G (1987) Intra- and post-operative blood loss and haemodynamics in total hip replacement when performed under lumbar epidural versus general anaesthesia. Eur J Anaesthesiol 4: 345-355.
Submit your next manuscript and get advantages of OMICS Group submissions

Unique features:

- User friendly/feasible website-translation of your paper to 50 world's leading languages

Audio Version of published paper

Digital articles to share and explore

Special features:

200 Open Access Journal

15,000 editorial team

21 days rapid review process

Quality and quick editorial, review and publication processing

- Indexing at PubMed (partial), Scopus, DOAJ, EBSCO, Index Copernicus and Google Scholar etc

Sharing Option: Social Networking Enabled

- Authors, Reviewers and Editors rewarded with online Scientific Credits

Better discount for your subsequent articles

Submit your manuscript at: http://www.editorialmanager.com/acrgroup/ 